\title{
Social work students on the island of Ireland: a cross-sectional survey
}

Claire McCartan, Julie Byrne, Jim Campbell, Declan Coogan, Gavin Davidson, David Hayes, Gloria Kirwan, Mandi MacDonald, Simone McCaughren, Paula McFadden, Caroline McGregor, Lorna Montgomery, Maria Pentaraki, Shaun Roddy, Audrey Roulston, Caroline Shore \& Elaine Wilson

To cite this article: Claire McCartan, Julie Byrne, Jim Campbell, Declan Coogan, Gavin Davidson, David Hayes, Gloria Kirwan, Mandi MacDonald, Simone McCaughren, Paula McFadden, Caroline McGregor, Lorna Montgomery, Maria Pentaraki, Shaun Roddy, Audrey Roulston, Caroline Shore \& Elaine Wilson (2020): Social work students on the island of Ireland: a cross-sectional survey, Social Work Education, DOI: 10.1080/02615479.2020.1832060

To link to this article: https://doi.org/10.1080/02615479.2020.1832060

\section{Published online: 14 Oct 2020.}

Submit your article to this journal $\longleftarrow$

山 Article views: 184

ai

View related articles $₫$

View Crossmark data $־$ 


\title{
Social work students on the island of Ireland: a cross-sectional survey
}

\author{
Claire McCartan ${ }^{a}$, Julie Byrne $\mathbb{B D}^{b}$, Jim Campbellc, Declan Coogan ${ }^{\mathrm{d}}$, Gavin Davidson ${ }^{\mathrm{a}}$, \\ David Hayes ${ }^{a}$, Gloria Kirwan ${ }^{b}$, Mandi MacDonald ${ }^{a}$, Simone McCaughren ${ }^{e}$, \\ Paula McFadden ${ }^{9}$, Caroline McGregor ${ }^{d}$, Lorna Montgomerya , Maria Pentarakia, \\ Shaun Roddy ${ }^{g}$, Audrey Roulston (iD) ${ }^{a}$, Caroline Shore ${ }^{\mathrm{e}}$ and Elaine Wilson (iD)
}

\begin{abstract}
aSchool of Social Sciences, Education \& Social Work, Queen's University Belfast, Belfast, UK; bSchool of Social Work \& Social Policy, Trinity College Dublin, Dublin, Ireland; 'School of Social Policy, Social Work \& Social

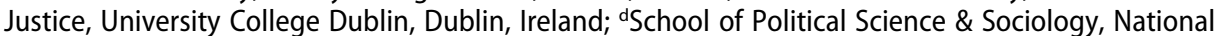
University of Ireland Galway, Galway, Ireland; 'eschool of Applied Social Studies, University College Cork, Cork, Ireland; fDepartment of Applied Social Studies, Maynooth University, Maynooth, Ireland; 9School of Applied Social \& Policy Sciences, Ulster University, Derry, UK
\end{abstract}

\begin{abstract}
Understanding the characteristics, motivations, and experiences of student social workers is important to inform their professional education and support needs. To date, there has been relatively little research about social work students in Ireland, both North and South. This study reports on an all-Ireland survey of students beginning their social work course in Autumn 2018 in the six Universities delivering social work education. It describes the characteristics of the student cohort, examines the motivations behind choosing this career, and highlights some of the potentially relevant life experiences and beliefswhich may have contributed to their ambition to join the social work profession. Implications for social work education, recommendations for curriculum development, workforce planning, and the provision of appropriate support for students are discussed.
\end{abstract}

\section{ARTICLE HISTORY}

Received 10 October 2019

Accepted 29 September 2020

\section{KEYWORDS}

Social work education; Ireland; curriculum development; student support; reflective practice

\section{Introduction: social work in Ireland, North and South}

There is an extensive literature base that explores student characteristics and motivations to study social work (Abell \& McDonell, 1990; Christie \& Kruk, 1998; Hackett et al., 2003; Stevens et al., 2012; Stoltzfus, 2017; Wilson \& McCrystal, 2007). If social work educators can better understand students' demographic characteristics, experiences, and motivating factors then the design and delivery of programs can be improved and tailored to: meet the learning needs of students; address pastoral issues; more effectively prepare students for practice; and so provide more effective interventions for service users (Christie \& Kruk, 1998).

The study, described below, sought to compare demographic characteristics of students, their relevant experiences, and their motivation to study to become social

CONTACT Claire McCartan c.j.mccartan@qub.ac.uk School of Social Sciences, Education \& Social Work, Queen's University Belfast, Belfast BT9 6AX., UK 
workers, on both sides of the Irish border. This involved the study of social work education in two jurisdictions, Northern Ireland (sometimes referred to as the North) which is part of the United Kingdom, and the Republic of Ireland (sometimes referred to as the South) which is an independent state. It was an opportunity, for the first time, systematically to compare and contrast forms of social work education across the island. Social work programs in these two jurisdictions, it can be argued, share many similarities in design and delivery. For example, all social work programs have inherited forms of competence-based learning approaches which were informed by policies and practices of the UK's Central Council for Social Work Education in the 1980s. College and placement curricula are similar in length of study and types of practice supervision. There are, however, some variations. For example, recruitment in each university varies (see Appendix 1) with the threshold for selection set by both the respective state regulators and academic institutions, as reflected in the international literature (Shaw, 1985; Campbell, Campbell \& Das, 2012).

In the North, all student social workers must register with the state regulator, the Northern Ireland Social Care Council (NISCC), from the start of their training and are subject to their requirements of disclosing any information that may be relevant to their fitness to practice (Northern Ireland Social Care Council, 2019). As a consequence, they are required to inform both the University and NISCC if they are service users or have health issues or criminal convictions which may prevent registration with NISCC, and which may ultimately lead to withdrawal from the course. The impact of this requirement on levels of disclosure is not known. In the South, CORU is the state body that regulates the social work profession as well as accrediting the educational programs (CORU, 2019). Students cannot register with CORU; however, many institutions have fitness to study procedures and conduct Garda (police) vetting on applicants. Graduates of any of the accredited programs may apply to register with CORU and must do so if they intend to use the title social worker. As in the North, the programs in the South have their own fitness to practice policies and students are required to disclose any relevant information on entry to the programs.

Although there are many similarities in terms of social work education, practice, and organizational delivery across both jurisdictions, the social and political contexts that inform social work education suggest diversion. Since the partition of Ireland in 1921, the North has experienced sustained levels of political conflict and sectarianism which have adversely affected many aspects of social work policy, practice, and education (Campbell, Duffy \& Simpson, 2016; Campbell \& McCrystal, 2005). The violence of the civil war in the South was confined to the 1920s, but other, different factors were at play in the $20^{\text {th }}$ Century, in particular the role of the Church in shaping public attitudes and the delivery of social services (Campbell \& McCrystal, 2005; Christie et al., 2015). Some of these predominantly conservative discourses have been replaced by new, more liberal ideas over the last decade. For example, there have been gradual, albeit problematic moves towards conflict resolution in the North, and the impact of new social movements has led to the repeal of outdated laws on abortion and homosexuality. In the South, public engagement has been harnessed leading to high voter turnout in social issue referenda and significant changes made to social policy and the Irish constitution. This has resulted in the liberalization of marriage, abortion, and divorce law. It also is important to highlight socio-economic contrasts between the two jurisdictions. Northern Ireland is 
a relatively impoverished part of the UK, whereas the South experienced intermittent periods of high economic growth over the last few decades. Such factors may affect the types of students recruited to social work programs and the levels of social disadvantage experienced by service users (Campbell \& Pinkerton, 2020).

\section{Motivations to become a social worker}

The literature suggests that there are complex factors which may influence decisions to apply for social work programs and then become a professional.

\section{The personal and political}

It has been argued that individual reward rather than altruistic intentions may be an important motivating factor (Christie \& Kruk, 1998; O’Conner et al., 1984), or that there may be an underlying type of personal fulfillment or a shared value base in making decisions (Holme \& Maizels, 1978; Uttley, 1981). In contrast to analyses that focus on the 'the personal', arguments about social and political structures are often referred to. Pearson's (1973) seminal ideas characterized such choices in terms of the "explicit rejection of "normal" values of everyday life' (Pearson, 1973 in Wilson \& McCrystal, 2007, p. 223) reflecting a sense of 'some form of political rebellion' (Pearson, 1973, p. 209). Abell and McDonell (1990) suggest that students are often motivated by a commitment to serve poor and disadvantaged communities. It is important to consider the negative connotations associated with social work practice and how these may or may not impact on motivation and choice. A career in social work is unlikely to attract a high income (Campanini \& Facchini, 2013), and problems of public image can erode professional status (Zugazaga et al., 2006). Social work is often considered to be challenging, involving complex and distressing problems, operating under substantial economic pressures and often subject to intense public and private scrutiny, which requires some degree of resilience. It may be the case that these disadvantages are counterbalanced with a belief in the worth of challenging social injustice, as Hackett et al. (2003) found in their study of the motivation of social work university students in four European countries. This commitment to a politically motivated and engaged role, one which can challenge the state and promote social justice and which changes over time and in different contexts, has been recently articulated (Ferguson et al., 2018). Thus, a sense of professional and personal reward (Holme \& Maizels, 1978; Solas, 1994) may follow from this engagement with issues of politics and society.

\section{Issues of identity and life experience}

Career motivation is also likely to be influenced by life experience, family background, personal needs, and beliefs (Albek, 1987; Rompf \& Royse, 1994; Stevens et al., 2012; Wilson \& McCrystal, 2007). Depending on the context, identities of race, ethnicity, and class are of significance for the social work education and the wider profession (Bini et al., 2019). Thus, concerns have been expressed about how experiences of racism are reinforced in social work programs in England (Fairtlough et al., 2014) and sectarianism in Northern Ireland (Smyth \& Campbell, 1996). Some authors have explored ways in which social workers understand poverty, class, and social exclusion (Delavega et al., 2017). In many countries social work remains a mostly female profession, but, as in other 
occupations, men tend to be overrepresented in management positions (Campanini \& Facchini, 2013; Stromberg, 1988). While social work continues to be a popular profession, the job can be highly stressful. Career lengths are shorter when compared to many other professions, and burnout is a specific area of concern (Lloyd et al., 2002). Social work students may also have greater exposure to significant life events that may have motivated their career choice in the first place (Christie \& Weeks, 1998), but which may adversely affect them when they experience such stressors in practice encounters. The status of being an expert with lived experience can help students and practitioners contribute to their understanding of the role and capacity to help. More negatively, shame and stigma are often associated with being a service user may lead social work students to be fearful of being open about their own needs where 'help seeking can be viewed as an act of weakness' (Newcomb et al., 2017a, p. 3). As Fox (2016) has argued, it is crucial that the value of experiential wisdom is recognized by social work programs in preventing such attitudes and preparing students for effective, thoughtful practice with service users.

A number of US studies have identified relatively high levels of mental health problems experienced by social work students associated with the use of medication, and depression and anxiety (Davis-Berman \& Pestello, 2002); high levels of psychiatric morbidity have also been found (Horton et al., 2009). It may be that social work educators struggle to understand how to meet the needs of students with mental health problems, and although insider knowledge and experience of services is valuable, as described above, it is not routinely acknowledged in the curriculum (Newcomb et al., 2017b). A comparative study of Australian programs (Gair \& Baglow, 2018) explored how financial and other hardships impacted on the mental health and well-being of respondents, recommending changes to curriculum and forms of support by institutions. The issue of ACEs was explored in Pooler et al.'s (2012) study of secondary data about 25 social work students. More than a quarter reported a parent with mental health and substance abuse problems and, to a lesser extent, substance, and mental health problems in their family histories.

\section{Methods}

The study involved social work students studying in the six institutions delivering social work programs in Ireland: National University of Ireland, Galway (NUI Galway); Queen's University Belfast (QUB); Trinity College Dublin (TCD); Ulster University (UU); University College Cork (UCC); and University College Dublin (UCD). The research design comprised a mixed-methods approach using an anonymized online survey of current social work students in the academic year 2018/19. All students were in their first year of study, apart from those in UCC who were in the third year of a fouryear Bachelor's program, and participating in the first of two professional practice placements. These students are judged to be comparable in terms of progress, to Masters in Social Work (MSW) students at the beginning of year 1 in the other programs.

The study received ethical approval from the research ethics committees in each of the institutions. There were some important specific ethical considerations for this research. The potential participants were at the start of their social work course and so there were issues of power and the possibility of students feeling under pressure to participate. In order to address these concerns, it was explained to all potential participants that their participation was entirely voluntary and that the social work staff involved would not be aware of who had participated or 
declined. In order to ensure this, a colleague in each University, who was not directly involved in the teaching and assessment of the relevant students, held the list of potential participants, allocated their unique code and sent all the correspondence to students with the relevant participant information. It was also possible for participants to opt-out of any section or a specific question on the survey and withdraw at any point until their anonymized responses had been submitted. Another specific issue was that no identifying data were shared between the six Universities and that all the data were stored securely. As mentioned, each list of students and their unique codes were held by a colleague not involved in social work assessment in each University and these identifying data were not shared. Only the anonymized data set was shared across the Universities and all data were stored in passwordprotected files on encrypted University drives and will be retained for 5 years. The survey also asks about potentially sensitive issues. This was explained in the participant information and University-specific information provided about how to access support if participants found anything in the survey to be distressing. Reminders were included in the survey itself that participants could also opt-out of answering any of the questions.

\section{Measures}

The aim of the study was to establish the demographic characteristics of applicants and explore beliefs about politics and society, and what factors informed their motivation to become a social worker. The survey captured demographic information about students' age, gender, sexual orientation, religious identity, and political identity, disability, and number and age of dependents. Data were gathered on past and current unpaid and paid caregiving, financial coping, perceived social class, and experiences of discrimination. Participants were also asked to identify which areas of social work they planned to work in once qualified and invited to comment on any concerns they had about entering the profession. Standardized measures were used to explore concepts of resilience (The 14-Item Resilience Scale (RS-14) (Wagnild, 2016)) and Adverse Childhood Experiences (ACEs) (Felitti \& Anda, 2010).

Motivation to study social work was assessed using a nine-item, six-point Likert scale constructed from themes in the literature. Respondents were asked to rate the nine statements from 1 to 6 ( 1 'not important at all' to 6 'extremely important'): I want to help people; I want to help people overcome oppression; because of personal experiences; I want a stable job; because it's consistent with my political beliefs; I've had good personal experience of social workers; I want to be a professional; I didn't know what else to do.

The Resilience Scale, developed by Wagnild and Young (1993), measures five underlying characteristics of resilience (the Resilience Core: purpose; perseverance; equanimity; self-reliance; existential aloneness (authenticity)) that enable people to 'bounce back, learn, and grow from life's difficulties' (Wagnild, 2016, p. 16). The short 14-item version has high reliability $(\alpha=0.91-0.94)$ and is scored on a range from 14 to 98 . Participants were asked to rate whether they strongly disagreed or agreed with 14 statements including: 'I feel I can handle many things at a time'; 'My life has meaning'; 'I can usually find something to laugh about'; 'Self-discipline is important'; 'My belief in myself gets me through hard times'. Total scores were banded to indicate 'Very low' (14-56), 'Low' (57-64), 'On the low end' (65-73), 'Moderate' (74-81), 'Moderately high' (82-90) and 'High' (91-98) resilience. 
Adverse Childhood Experiences (ACEs) were measured using a form of the ACEs Questionnaire (Felitti et al., 1998). Students were asked to read 10 statements and respond 'yes' (1) or 'no' (0) if these events happened OFTEN while they were growing up before the age of 18. The statements were used to indicate childhood experiences of abuse and neglect and highlight other areas of household dysfunction during childhood including domestic violence, incarceration, and alcohol and drug misuse. A total ACEs score was calculated based on the number of affirmative answers; each incremental rise in the ACEs score is associated with a graded dose-response relationship with a large range of negative health and wellbeing outcomes (Anda et al., 2010).

The survey, therefore, collected a considerable amount of data on a wide range of potential issues. The purpose of this article is to provide an initial overview of the results and highlight some of the key issues. There are a number of aspects of the data which we plan to explore further and the participants will also be followed up at the end of their social work courses to explore possible change over time.

\section{Results}

\section{Participants}

A total of 240 students completed the survey (response rate of 53.6\%) (Table 1). This included students who were studying the 2-year Relevant Graduate Route (RGR) and 3-year Undergraduate Route (UGR) pathways at QUB and UU in Northern Ireland. Students in the Republic of Ireland were recruited from the four-year Bachelor in Social Work (BSW) and Masters in Social Work (MSW) at UCC and the Bachelor of Social Studies and MSW in TCD. In NUI Galway and UCD, MSW students were surveyed.

The majority of students were aged between 23 and 30 years (40.1\%); 31-40 year olds were the next largest group (20.3\%), with 19-22 year olds (19.4\%) and 41-50 year olds (14.8\%) making up one-third of participants. The youngest students were under 19 years old and the eldest aged between 51 and 60 years old; both these age categories comprised less than $10 \%$ of total respondents. The large majority of participants were female (83.3\%), reflecting the typical gender imbalance in student social work populations in other jurisdictions (Schaub, 2015). Gender profiles varied between universities and pathways; University College Cork had the largest proportion of male student participants and males were more represented in the BSW 3

Table 1. Participants by university, gender, and pathway.

\begin{tabular}{llccccc}
\hline University & Pathway & $N$ & Cohort response rate & \% of total sample & Female (0\%) & Male (0\%) \\
\hline NUI GALWAY & MSW & 8 & 40.0 & 3.3 & 100.0 & 0.0 \\
QUB & UGR & 33 & 45.8 & 13.8 & 84.8 & 15.2 \\
QUB & RGR & 18 & 45.0 & 7.5 & 94.4 & 5.6 \\
TCD & BSS & 18 & 36.7 & 7.5 & 83.3 & 16.7 \\
TCD & MSW & 19 & 90.5 & 7.9 & 89.5 & 10.5 \\
UCC & BSW & 12 & 92.4 & 5.0 & 58.3 & 41.7 \\
UCC & MSW & 24 & 88.9 & 16.7 & 82.5 & 17.5 \\
UCD & MSW & 24 & 52.2 & 10.0 & 79.2 & 20.8 \\
UU & UGR & 54 & 50.0 & 22.5 & 81.5 & 18.5 \\
UU & RGR & 14 & 35.0 & 5.8 & 85.7 & 14.3 \\
UNDERGRADUATE & ROUTE & 117 & 26.1 & 48.8 & 80.3 & 19.7 \\
RGR/MSW ROUTE & 123 & 27.5 & 51.3 & 86.2 & 13.8 \\
TOTAL & 240 & 53.6 & 100.0 & 83.3 & 16.7 \\
\hline
\end{tabular}


or 4 year programs (19.7\%) compared to the MSW 2 year pathways (13.8\%). Similar numbers of students were born in the Republic of Ireland (42.7\%) and Northern Ireland (41.8\%) however none of the students studying in the Republic of Ireland had been born in Northern Ireland and only a very small number of students in the North had been born in the South. Just over fifteen per cent (15.5\%) of participants were born elsewhere, including North and South America, Africa, and elsewhere in Europe.

Many students were already well qualified prior to enrolment. The highest previous qualification of over half of students was at undergraduate degree level (51.9\%) while onethird had achieved A Levels/Leaving Certificate/Access level equivalent. Fifteen per cent of students had Masters (4.2\%) or postgraduate diploma qualifications (11.8\%). Comparing the undergraduate route pathways, a high number of QUB's UGR had already obtained an undergraduate degree (39.4\%) or postgraduate level qualification $(21.2 \%)$, half of the small cohort of UCC BSW students also had an undergraduate or postgraduate qualification and for UU UGR students, $27.5 \%$ had studied at undergraduate, postgraduate, or Masters level.

Almost $14 \%$ of respondents (13.8\%) described themselves as having a disability relating to a physical $(4.2 \%)$ or mental health condition (2.9\%); a number of students also reported a learning disability (dyslexia) or sensory impairment. A large proportion of respondents were single $(40.5 \%)$ and over one quarter $(27.0 \%)$ were in relationship but not living with their partner. A third of participants were either married (16.9\%) or cohabiting $(11.8 \%)$. A small number were divorced, widowed, or described themselves as 'other.' Most respondents (96.3\%) categorized themselves as heterosexual with a very small number identifying as gay, lesbian, or bisexual. Ninety-five per cent of participants described their ethnic group as white reflecting the profile reported in the most recent census in both jurisdictions $(92.4 \%$, Irish Census 2016; 98.3\%, Northern Ireland Census 2011).

\section{Areas of social work}

Students were asked to select from a list of areas of social work they would most like to work (Figure 1). 'Child care, welfare and protection' was clearly the most popular area

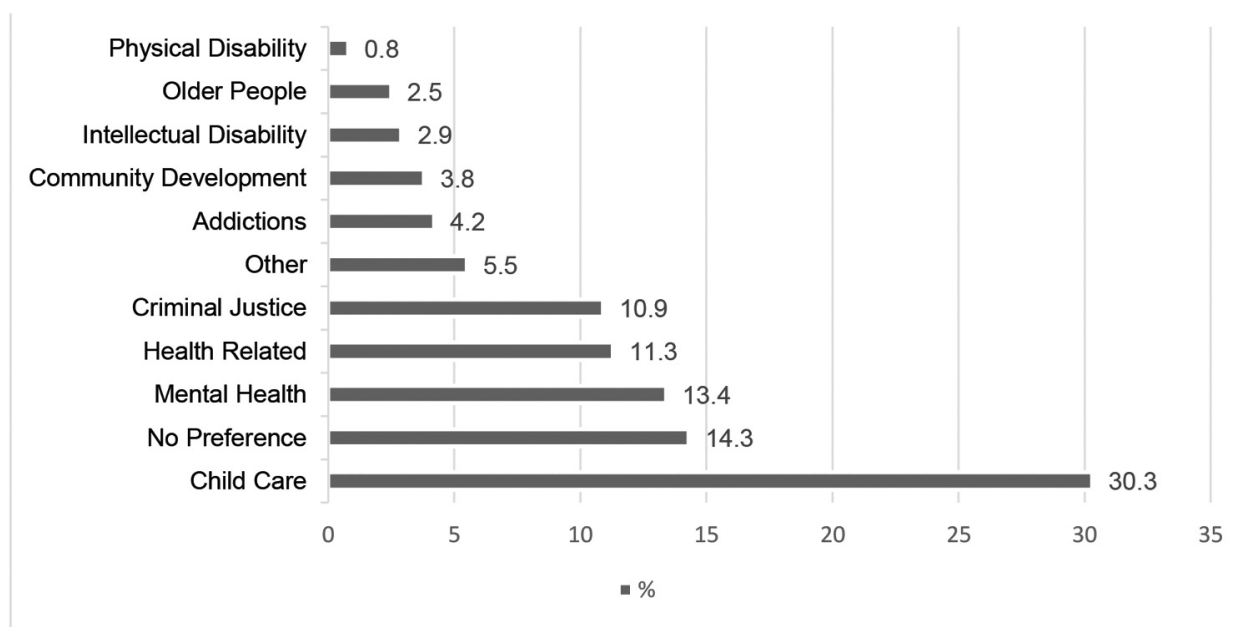

Figure 1. What area of social work would you most like to work? 
(30.3\%), followed by 'mental health' (13.4\%), 'health-related' (11.3\%) and 'criminal justice' (10.9\%) but a large number of respondents also stated no preference $(14.3 \%)$. Areas including physical disability, older people, intellectual disability, community development, and addictions were much less popular. Students were also asked if they had any concerns about being a social worker. Many had fears about working in the profession (58.2\%) and the majority of the qualitative responses to this question related to stress, burnout, pressure, workload, and personal resilience.

\section{Relevant life experience}

\section{Experiences of providing care \& social services}

A proportion of participants had experiences of providing care to others. Almost onethird of students had children $(n=77 ; 32.4 \%$; mean $=2.1$ (SD 1.16; range 1 to 5 ). Some parents had very young children aged between 0 and 4 years (12.9\%) including a number of children under 1 year old (3.75\%).

A number of students had personal experience of social services with over one quarter $(28.4 \%)$ of the sample reporting past contact; a small number were current service users (6.4\%). Experiences varied from receipt of family and childcare services for child protection or out of home care issues, work experience to mental health treatment services for self or other family members. Many also reported previous experience of both unpaid (48.6\%) and paid care $(51.9 \%)$ to others (not their own children). This ranged from voluntary work placements or caring for close family members. This is unsurprising given the benefits of relevant work experience when applying to social work courses. Many institutions also require substantial relevant experience for course admission, for example, the TCD MSW requirement is set at 850 hours of paid or voluntary practice experience.

Being a student had an impact on unpaid care rates with a much lower number of students currently undertaking unpaid care work (16.9\%)-this may reflect the reduced need for work experience once accepted on a course or indicate the demands of full-time study. However, a large number of students continue to supplement their income by undertaking paid care work (30\%) or other forms of employment including administration, call center work, bar work/waiting, and retail (34.6\%). Students were asked about how well they were 'managing financially these days,' most described themselves as 'doing alright' (33.3\%) or 'just about getting by' (35.4\%). Around $20 \%$ of the cohort were finding it quite $(13.5 \%)$ or very difficult $(6.8 \%)$ to manage.

\section{Beliefs and motivation}

\section{Motivation to study social work}

Respondents were asked to choose from a range of choices to identify what factors informed their motivation to apply for the program (Figure 2). These can be rankordered as follows: 'wanting to help people' (86.3\%); 'overcome oppression' $(66.4 \%)$. Being a professional (33.6\%), personal experiences (32.5\%), and job stability (32\%) were also identified as important factors. Political beliefs were rated as not important at all by $42 \%$ of respondents. Experiences of social work (either good (39.5\%) or bad 


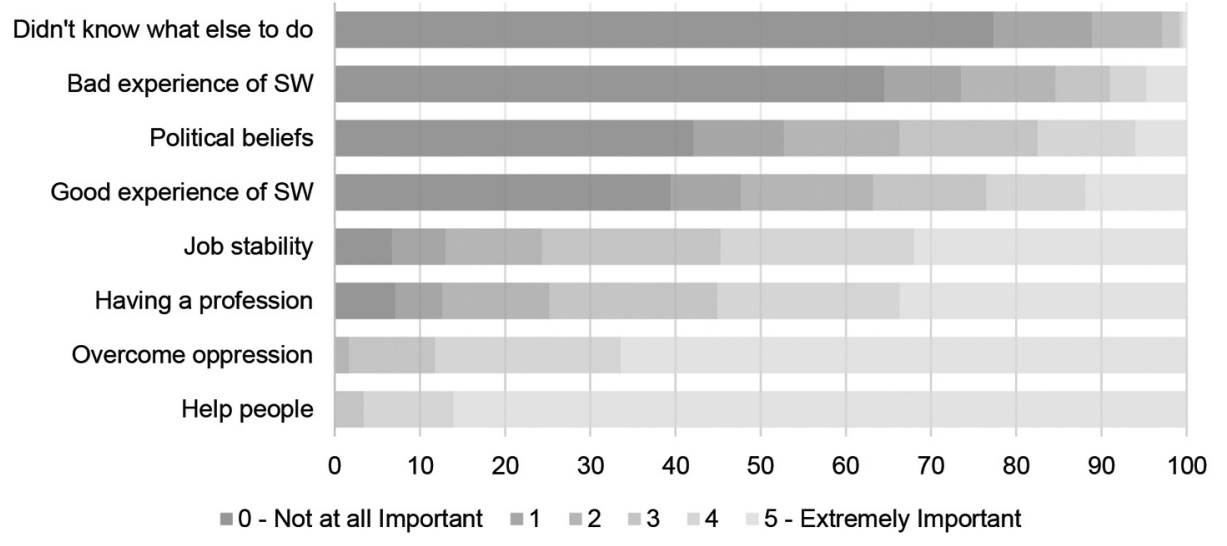

Figure 2. Motivation to study social work.

$(64.5 \%))$, or not knowing what other career to choose $(77.1 \%)$ were considered to be unimportant.

\section{Political beliefs and self-perceptions of class}

Students were asked to rank in order of importance, their political opinions (Figure 3), with 1 being the most important, 2 the second most important and so on, for as many of

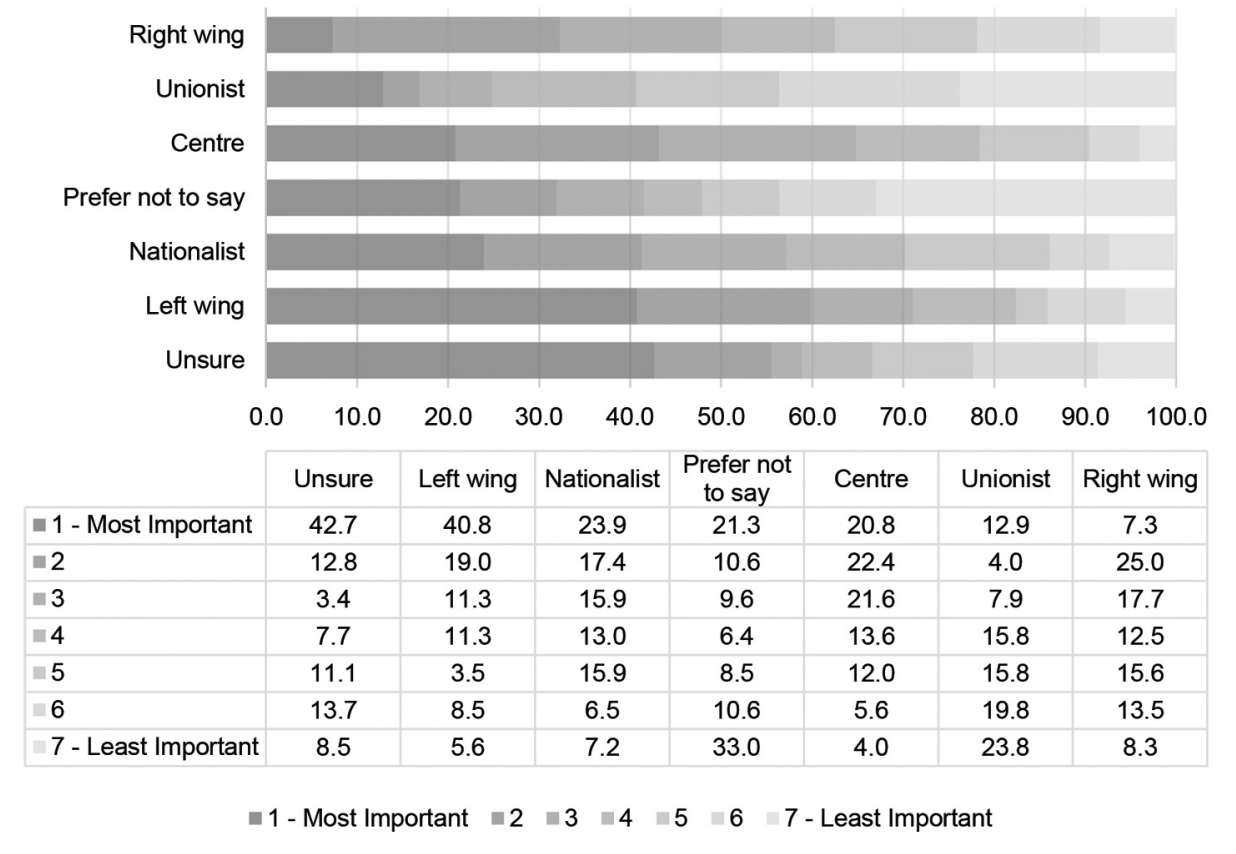

Figure 3. Political beliefs. 
the following categories that applied: Left wing; Centre; Right wing; Unionist; Nationalist (it should be noted that these categories were more likely to be relevant to students from Northern Ireland but it was considered important to include this potential complexity of views); Unsure; and Prefer not to say. Nearly all respondents chose either Unsure (42.7\%) or Left wing (40.8\%) and were much less likely to use the categories of Right wing, Unionist and Nationalist or Prefer not to say.

Students were asked to consider how they viewed themselves in terms of class. In terms of the whole population, $42.7 \%$ were middle class and 56.3 working class. Interestingly, Southern students were more likely to describe themselves as middle class (over two-thirds) when compared to Northern students (around one-third). This may reflect the different political and social contexts in either side of the border, discussed above.

\section{Mental health, adverse childhood experiences and resilience}

Two survey items examined mental health issues. Students were asked if they had a disability and these were coded to include a mental health-related condition and in a separate question at the end of the survey, participants were asked to rate their mental health on a scale of $0-100$ ( 0 being the worst I can imagine to 100 being the best). The large majority of participants fell within the highest deciles reporting relatively good mental health correlating with the self-report of mental health.

\section{Adverse childhood experiences}

The ACEs questionnaire covers a range of sensitive items and respondents were reminded that they need not answer all of the questions (Figure 4). The response rate to this section was slightly lower than the other survey items with $10.4 \%$ of participants declining to complete the full questionnaire. Of the 215 respondents, $30.2 \%$ reported 0 ACEs, $49.8 \%$ had between 1 and 3 ACEs and 20.1\% reported 4 or more. A Mann-Whitney $U$ test showed that there was no significant difference $(\mathrm{U}=5709.5, \mathrm{p}=.889)$ in the total ACEs score of students from the North or the

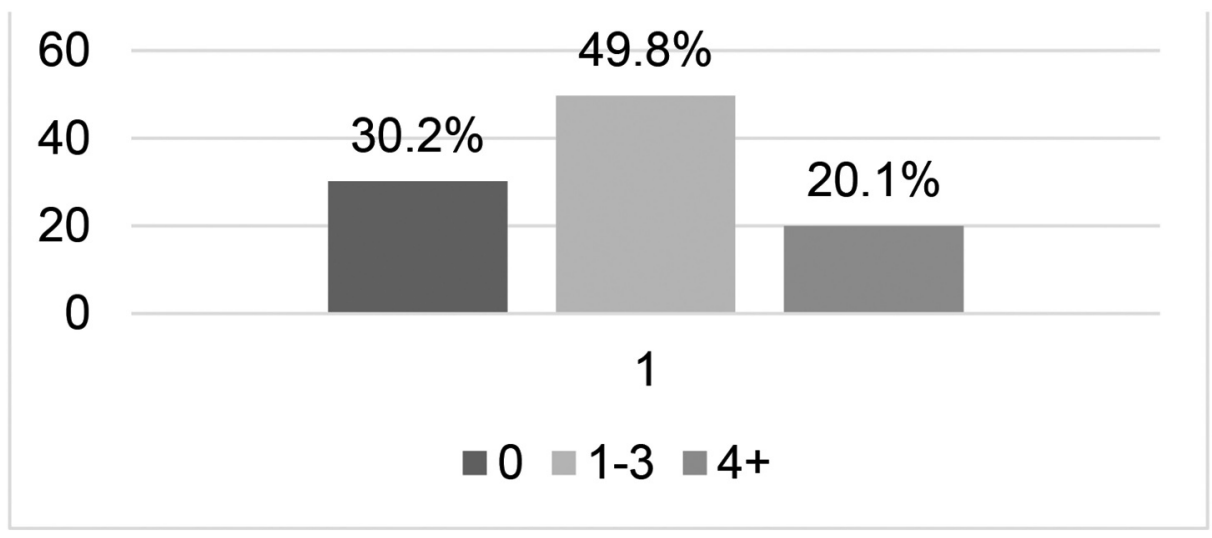

Figure 4. Number of ACEs. 
South. The total ACEs scores were higher than another recent prevalence study of a first-year university student cohort in Northern Ireland (McGavock \& Spratt, 2014) which found lower rates of 0 ACEs (43.9\%), 1-3 ACEs (43.5\%) and 4 or more ACEs (12.4\%). Caution must be observed making a direct comparison with the larger sample size $(\mathrm{N}=765)$ in the McGavock and Spratt study but is does indicate that social work students in our study compared to the general student population may have higher rates of ACEs.

\section{Resilience}

The 14-item Resilience Scale indicated that the majority of respondents reported moderate to high levels of resilience (Figure 5) ('Moderate'-indicating neither low or high resilience, possessing many characteristics of resilience (27.8\%); 'Moderately high'-you're doing well but feel you could improve (26.6\%); and 'High'-doing very well in almost all aspects of resilience (15.3\%)). Less than $6 \%$ of participants were considered to have 'Low' $(3.8 \%)$ or 'Very low' $(2.1 \%)$ resilience. Low levels of resilience have been associated with depression and anxiety (Wagnild, 2016). The generally positive resilience ratings are encouraging in light of the higher ACEs scores reporting compared to the general student population. Once again, a MannWhitney $U$ test showed that there were no statistically significant scores between the North and South $(\mathrm{U}=6,268.5, \mathrm{p}=.814)$.

\section{Discussion}

Bearing in mind the study limitations described below, these results raise some important issues for social work education and practice in Irish universities.

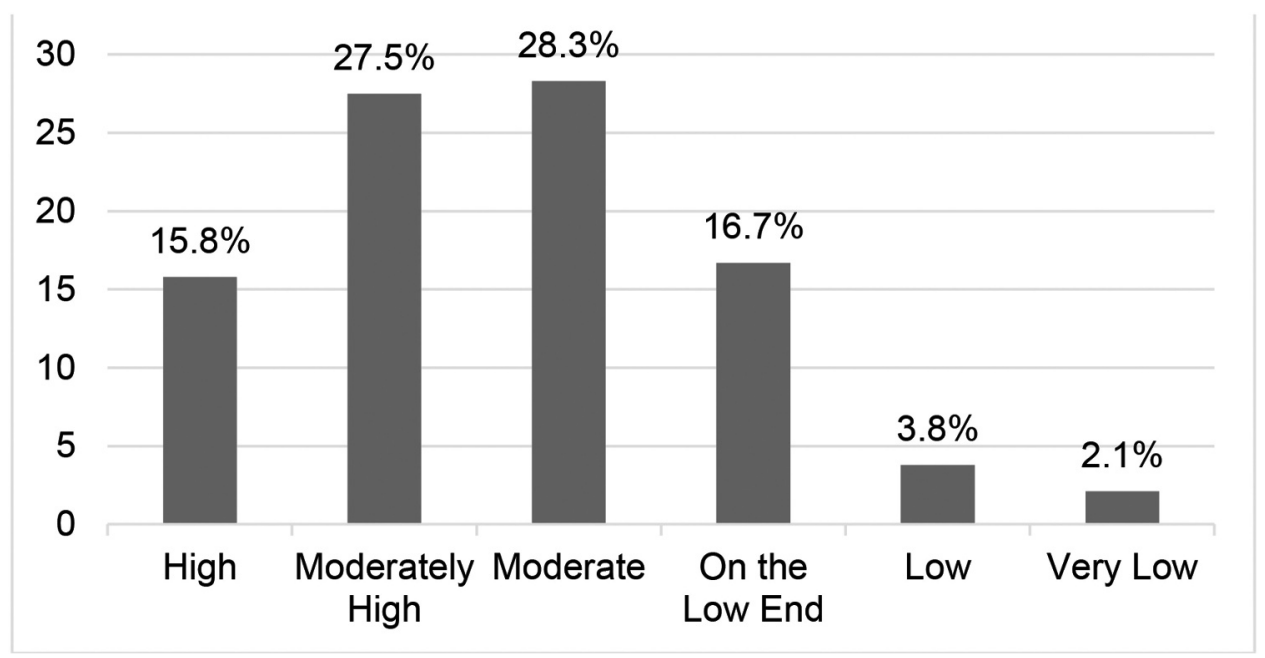

Figure 5. Resilience scale. 


\section{Demographic profiles}

An ongoing issue for the profession is the demographic representativeness of the cohort as they enter the workforce. As in other jurisdictions, Irish social work students are mostly women, although in a few institutions, men were more represented (UCC BSW, 32.1\% male; MSW 21.6\% male) and TCD Bachelor in Social Studies 22.5\% per cent. As discussed in the review of literature, men tend to rise more quickly in academic and managerial positions reflecting a pattern of vertical gender segregation (Christie, 1998, 2001). There were relatively few students with Black and Minority Ethnic backgrounds, however there is recent interest in the Irish Association of Social Workers in establishing a network to protect the interests of students and practitioners who may be subject to the type of racism found in other jurisdictions (Fairtlough et al., 2014). These findings suggest that institutions, programmes, and the wider social work community needs to further challenge such demographic imbalances. Many of the students had already completed undergraduate and postgraduate qualifications, the reasons for this varied, including the competitiveness of course admissions, older average age of cohorts compared to other third-level courses.

\section{Personal and family experiences}

Well over one-quarter of students had some personal experience of social services or social work contact in their lives, as the literature indicates, this can be a positive attribute, for example in terms of personal development and how this experience is used during education and practice. On the other hand, social work programs need to be sensitive about the possible burden of such experiences and how others view these. Given the diverse age range, and gendered backgrounds of the respondents it is not surprising that many were involved in caring responsibilities. It seems alarming that $37.6 \%$ of participants identified bad experiences of social work as part of their motivation to become a social worker; and, within those, $9 \%$ rated bad experiences as an important or extremely important motivation. Although it is positive that these students were motivated to prevent these bad experiences for others, it raises the question of the level of negative experiences in the general population and how these should be addressed. There was a mixed picture in terms of health and well-being. Although mental health needs were generally reported in positive terms, the relatively high rates of ACEs suggest that educators need to understand possible immediate and long-term physical and mental health outcomes for a number of students, when engaging with training in sensitive areas of practice. Interestingly, the result of the survey found respondents to report relatively high levels of resilience which may help protect them in future stressful practice contexts.

\section{Issues of social justice and politics}

It was evident from the results that many students, across all the institutions, were motivated by the prospect of influencing social change and justice, presumably there was an assumption that becoming a social worker could achieve this aspiration. This confirms themes on this topic in the social work literature (Manktelow et al., 2002). When asked 
about political beliefs, the results were more ambiguous. An assumption may be made that the positioning of the profession between state and civil society, and concerns about issues of social justice, would attract students who might be judged to be 'left of centre,' which was the case in the Irish study. What is interesting were the many students who were unsure of their political beliefs $(42.7 \%)$ or did not wish to divulge their political ideologies, perhaps because this position did not fit with their perspectives on politics. It will be interesting to see if these perspectives on political beliefs and issues change over time. The lack of positive responses to questions about nationalist and unionist identities which was most relevant to Northern students is more explainable. The enduring legacy of the conflict in Northern Ireland has had the effect of closing down dialog between communities and the use of silence and hidden identities were used as coping mechanisms to avoid conflict and pain (Campbell, Ioakimidis \& Maglajilic, 2019). It also raises the issue of whether and how these issues of political belief and their relevance to social work practice should be explored across the courses.

\section{Recommendations for curriculum development}

It is crucial that social work educators ensure that they understand the personal and family lives of students and the belief systems that have motivated them to become professionals. The evidence from this study implies that Irish universities should design timetables and assessments to deal with the personal issues that students bring to the classroom. It is also important that social work education continues to reflect and build on the growing diversity within the wider population and prepare students well for progressive and anti-oppressive forms of practice. Understanding why students are motivated to join the profession and harnessing these motivations is crucial. Creating learning opportunities that teach students how to recognize and challenge the structural causes of oppression could help engage with such motivations. A recent example of this in Northern Ireland has been the government's production of a number of professional framework guides that refocus attention on the social justice role of the profession. Advice and guidance in these resources encourage the profession to reengage with the lobbying and advocacy role of social work (Department of Health NI, 2018).

\section{Implications for workforce planning}

The study explored how social work students in these programs viewed the future choice of practice contexts. Many chose areas of childcare, protection, and welfare, perhaps because these were areas of higher employment, but others were unsure about preferences. It may be too early in the degree course for these respondents to identify the final area of choice, but these early indications have implications for workforce planning and recruitment. On the other hand relatively low numbers of students chose areas in aspects of adult services. As these become more important areas of service delivery, particularly with an increasing elderly population and more and more people with complex health and social care needs, educators and employers should reflect upon the design of social work programs as they plan services. 


\section{Conclusion}

This is the first, comparative survey of its kind in the island of Ireland involving a collaboration across the six universities delivering social work education both North and South. It provides insights into the demographics, motivations, beliefs, and aspirations of the social work student cohort and highlights some areas for the provision of support and learning for current and future students. It is apparent that the student body are highly qualified in terms of education and experiences of providing unpaid and paid care to others. The study revealed aspects of ACEs and relatively high levels of resilience, issues which if regularly monitored longitudinally as new cohorts enter the academy could help educators to sensitively design the curricula to meet personal needs. These are relatively heterogeneous cohorts in terms of issues of class, ethnicity, and reported sexual orientation students. Whilst social work remains a mostly female, middle-class occupation, this continues to challenge the academic institutions and the profession.

At this early stage of their career, child care and mental health were the most popular areas of intended practice. It would be important to track this over the course of the degree program to help identify where deficits may be and consider extending learning and practice opportunities to promote careers in other areas of social work. Fear of burnout and stress is affecting over half of the students and the importance of self-care should continue to be an area of focus for academics preparing their student cohort. Those involved in teaching students also have a responsibility to promote, lobby, and advocate for the profession with students, regulators, service providers, and professional associations.

Many of those motivated to join the profession are driven by social justice principles and it is important that this commitment continues to be a fundamental part of social work education-supporting the aspirations of those wishing to become social workers and providing them with the skills, experiences, and opportunities to fight oppression and help others.

This research is continuing in the expectation that more meaningful, longitudinal data can be analyzed by tracking these cohorts to the completion of their studies, as well exploring a number of subset issues that have emerged from this overview. It is hoped that these initiatives will reveal more about the backgrounds, beliefs, and motivations of Irish social work students as we move into the next decade.

\section{Notes}

1. The Central Applications Office processes applications for undergraduate courses in Irish Higher Education Institutions.

2. Mature Students Admissions Pathway.

\section{Acknowledgments}

This project was supported by the Office of Social Services, Department of Health, Northern Ireland, and the Northern Ireland Social Care Council. 


\section{Disclosure statement}

No potential conflict of interest was reported by the author(s).

\section{Ethical approval}

Ethical approval was granted by the Research Ethics Committee in the School of Social Sciences, Education and Social Work at QUB.

\section{Missing data availability}

The data that support the findings of this study are available on request from the corresponding author, $[\mathrm{CMcC}]$. The data are not publicly available due to [restrictions e.g. their containing information that could compromise the privacy of research participants].

\section{Study limitations}

The topic areas explored in the study were based on a review of the relevant research literature and there may well be other important aspects of people's lives that we did not ask about. Despite the survey being anonymized at source, there is a potential for response bias, particularly where course sample sizes were small. We are also not in a position to comment on the nonresponse bias of those choosing not to participate in the survey. As a cross-sectional survey, it only reflects students' views at a given point in time.

\section{Notes on contributors}

Julie Byrne is an Assistant Professor in Online Education and Development in the School of Social Work and Social Policy at Trinity College Dublin (TCD).

Jim Campbell is Chair of Social Work at University College Dublin (UCD).

Declan Coogan is a Lecturer with the MA in Social Work Programme at the School of Political Science \& Sociology at NUI Galway and a systemic psychotherapist (FTAI).

Gavin Davidson is a Professor of Social Care in the School of Social Sciences, Education, and Social Work at Queen's University Belfast (QUB).

David Hayes is a Senior Lecturer in the School of Social Sciences, Education and Social Work at QUB.

Gloria Kirwan is a Lecturer in Social Work in the Department of Applied Social Studies at Maynooth University.

Mandi MacDonald is a Senior Lecturer in Social Work in the School of Social Sciences, Education and Social Work at QUB.

Claire McCartan is a Research Fellow in the School of Social Sciences, Education and Social Work QUB.

Simone McCaughren is a Lecturer in the School of Applied Social Studies at University College Cork (UCC).

Paula McFadden is a Senior Lecturer in Social Work in the School of Applied Social and Policy Sciences at Ulster University (UU).

Caroline McGregor is a Professor at the School of Political Science and Sociology at NUI Galway. 
Lorna Montgomery is a Senior Lecturer and Director of Practice Learning for the BSW in the School of Social Sciences, Education and Social Work at QUB.

Maria Pentaraki is a Lecturer in Social Work in the School of Social Sciences, Education and Social Work at QUB.

Shaun Roddy is a Lecturer in Social Work at Ulster University.

Audrey Roulston is a Senior Lecturer in Social Work in the School of Social Sciences, Education and Social Work at QUB.

Caroline Shore is a Lecturer and 1st Year Coordinator on the Master of Social Work course at UCC.

Elaine Wilson is Assistant Professor, Co-Director of the PMSW programme and Director of Professional Practice in the School of Social Policy, Social Work and Social Justice at UCD.

\section{References}

Abell, N., \& McDonell, J. R. (1990). Preparing for practice: Motivations, expectations and aspirations of the MSW class of 1990. Journal of Social Work Education, 26(1), 57-64. https://doi.org/ $10.1080 / 10437797.1990 .10672134$

Albek, S. (1987). The expectations from the selected profession. Society and Welfare, 8(1), 24-32.

Anda, R. F., Butchart, A., Felitti, V. J., \& Brown, D. W. (2010). Building a framework for global surveillance of the public health implications of adverse childhood experiences. American Journal of Preventive Medicine, 39(1), 93-98. https://doi.org/10.1016/j.amepre.2010.03.015

Bini, E., Vezzosi, E., Togni, C., Malatesta, D., Dellavalle, M., Ramos-Feijóo, C., \& Waaldijk, B. (2019). Gender and social work. New historical studies and interpretations. Contemporanea, 2 (April-June), 269-304. https://doi.org/10.1409/93532

Campanini, A., \& Facchini, C. (2013). Values and motivations in BA students of social work: The Italian case. Social Work \& Society, 11(1), 1-17. http://nbn-resolving.de/urn:nbn:de:hbz:464sws-472

Campbell, J., Duffy, J., \& Simpson, M. (2016). Political conflict and social work education. In I. Taylor, M. Bogo, M. Lefevre, \& B. Teater (Eds). Routledge International Handbook of Social Work Education (pp. 275-285). doi:10.4324/9781315712536

Campbell, J., Campbell, A., \& Das, C. (2012). A study of successful applicants' views of a social work admissions process. Journal of Social Work, 13(4), 382-399.

Campbell, J., Ioakimidis, V., \& Maglajlic, R. A. (2019). Social work for critical peace: A comparative approach to understanding social work and political conflict. European Journal of Social Work, 22(6), 1073-1084. https://doi.org/10.1080/13691457.2018.1462149

Campbell, J., \& McCrystal, P. (2005). Mental Health Social Work and the Troubles in Northern Ireland. Journal of Social Work, 5(2):173-190. doi:10.1177/1468017305054971

Campbell, J., \& Pinkerton, J. (2020). Social work, social justice and sectarianism in post-conflict northern Ireland. In G. Singh \& M. Shepard (Eds.), Anti-Racist Social Work. Basingstoke: Palgrave Macmillan.

Christie, A. (1998). Is social work a 'non-traditional' occupation for men? The British Journal of Social Work, 28(4), 491-510. https://doi.org/10.1093/oxfordjournals.bjsw.a011363

Christie, A. (2001). Men as social workers in the UK: Professional locations and gendering global discourses of welfare. In B. Pease \& K. Pringle (Eds.), A man's world? Changing men's practices in a globalized world (pp. 103-117). Zed Books.

Christie, A., Featherstone, B., Quin, S., \& Walsh, T. (Eds.). (2015). Social work in Ireland: Changes and continuities. Macmillan International Higher Education.

Christie, A., \& Kruk, E. (1998). Choosing to become a social worker: Motives, incentives, concerns and disincentives. Social Work Education, 17(1), 21-34. https://doi.org/10.1080/ 02615479811220031 
Christie, A., \& Weeks, J. (1998). Life experience: A neglected form of knowledge in social work education and practice. Social Work in Action, 10(1), 55-68. https://doi.org/10.1080/ 09503159808411477

CORU. (2019). Social workers registration board code of professional conduct and ethics.

Davis-Berman, J., \& Pestello, H. F. (2002). Psychiatric medication. Social Work in Mental Health, 1 (2), 31-42. https://doi.org/10.1300/J200v01n02_03

Delavega, E., Kindle, P. A., Peterson, S., \& Schwartz, C. (2017). The blame index: Exploring the change in social work students' perceptions of poverty. Journal of Social Work Education, 53(4), 664-675. https://doi.org/10.1080/10437797.2017.1287028

Department of Health NI. (2018). Anti-poverty practice framework for social work in Northern Ireland. Belfast: Department of Health NI. https://www.health-ni.gov.uk/sites/default/files/pub lications/health/Povertyframework.pdf

Fairtlough, A., Bernard, C., Fletcher, J., \& Ahmet, A. (2014). Black social work students' experiences of practice learning: Understanding differential progression rates. Journal of Social Work, 14(6), 605-624. https://doi.org/10.1177/1468017313500416

Felitti, V. J., \& Anda, R. F. (2010). The relationship of adverse childhood experiences to adult medical disease, psychiatric disorders, and sexual behavior: Implications for healthcare. In R. Lanius \& E. Vermetten (Eds.), The impact of early life trauma on health and disease: The hidden epidemic (pp. 77-87). Cambridge University Press.

Felitti, V. J., Anda, R. F., Nordenberg, D., Williamson, D. F., Spitz, A. M., Edwards, V., Koss, M. P., \& Marks, J. S. (1998). Relationship of childhood abuse and household dysfunction to many of the leading causes of death in adults. American Journal of Preventive Medicine, 14(4), 245-258. https://doi.org/10.1016/S0749-3797(98)00017-8

Ferguson, I., Ioakimidis, V., \& Lavlette, M. (2018). Global social work in a political context: Radical perspectives. Policy Press.

Fox, J. (2016). Being a service user and a social work academic: Balancing expert identities. Social Work Education, 35(8), 960-969. https://doi.org/10.1080/02615479.2016.1227315

Gair, S., \& Baglow, L. (2018). "We barely survived": Social work students' mental health vulnerabilities and implications for educators, universities and the workforce. Aotearoa New Zealand Social Work, 30(1), 32.44. https://anzswjournal.nz/anzsw/article/view/470/555

Hackett, S., Kuronen, M., Matthies, A.-L., \& Kresal, B. (2003). The motivation, professional development and identity of social work students in four European countries. European Journal of Social Work, 6(2), 163-178. https://doi.org/10.1080/1369145032000144421

Holme, A., \& Maizels, J. (1978). Social workers and volunteers. Allen \& Unwin London.

Horton, E. G., Diaz, N., \& Green, D. (2009). Mental health characteristics of social work students: implications for social work education. Social Work in Mental Health, 7(5), 458-475. https://doi. org/10.1080/15332980802467696

Lloyd, C., King, R., \& Chenoweth, L. (2002). Social work, stress and burnout: A review. Journal of Mental Health, 11(3), 255-265. https://doi.org/10.1080/09638230020023642

Manktelow, R., Hughes, P., Britton, F., Campbell, J., Hamilton, B., Wilson, G. (2002). The experience and practice of approved social workers in Northern Ireland. British Journal of Social Work, 32(4), 443-461. https://doi.org/10.1093/bjsw/32.4.443

McGavock, L., \& Spratt, T. (2014). Prevalence of adverse childhood experiences in a university population: Associations with use of social services. British Journal of Social Work, 44, 657-674. https://doi.org/10.1080/02615479.2017.1327574

Newcomb, M., Burton, J., \& Edwards, N. (2017a). Service user or service provider? How social work and human services students integrate dual identities. Social Work Education, 36(6), 678-689. https://doi.org/10.1080/02615479.2017.1327574

Newcomb, M., Burton, J., \& Edwards, N. (2017b). Childhood adversity and self-care education for undergraduate social work and human services students. Journal of Teaching in Social Work, 37 (4), 337-352. https://doi.org/10.1080/08841233.2017.1345821

Northern Ireland Social Care Council. (2019). Standards of conduct for social work students. NISCC. 
O’Conner, I., Dalgieish, L., \& Khan, J. (1984). A reflection of the rising spectre of conservatism: Motivational accounts of social work students. British Journal of Social Work, 14(1), 227-240. https://doi.org/10.1093/oxfordjournals.bjsw.a054955

Pearson, G. (1973). Social work as the privatized solution of public ills. The British Journal of Social Work, 3(2), 209-227. https://doi.org/10.1093/oxfordjournals.bjsw.a056400

Pooler, D. K., Doolittle, A., Faul, A. C., Barbee, A., \& Fuller, M. (2012). An exploration of msw field education and impairment prevention: what do we need to know? Journal of Human Behavior in the Social Environment, Vol, 22(7), 916-927. https://doi.org/10.1080/10911359.2012.707936

Rompf, E., \& Royse, D. (1994). Choice of social work as a career: Possible influences. Journal of Social Work Education, 30(2), 163-171. https://doi.org/10.1080/10437797.1994.10672227

Schaub, J. (2015). Issues for men's progression on english social work honours and postgraduate degree courses. Social Work Education, 34(3), 315-327. https://doi.org/10.1080/02615479.2014.997698

Shaw, I. (1985). A closed profession? Recruitment to social work. British Journal of Social Work, 15 (3), 261-280.

Smyth, M., \& Campbell. J. (1996). Social work, sectarianism and anti-sectarian practice in Northern Ireland. British Journal of Social Work, 26(1), 77-92.

Solas, J. (1994). Why enter social work? Why on Earth do they want to do it?: Recruits' ulterior motives for entering social work. Issues in Social Work Education, 14(2), 51-63.

Stevens, M., Moriarty, J., Manthorpe, J., Hussein, S., Sharpe, E., Orme, J., Mcyntyre, G., Cavanagh, K., Green-Lister, P., \& Crisp, B. R. (2012). Helping others or a rewarding career? Investigating student motivations to train as social workers in England. Journal of Social Work, 12(1), 16-36. https://doi.org/10.1177/1468017310380085

Stoltzfus, K. M. (2017). The motivation of Russian Federation social work students for pursuing a social work degree. International Social Work, 60(4), 847-860. https://doi.org/10.1177/ 0020872815580043

Stromberg, A. (1988). Women in female-dominated professions. In A. Stromberg \& S. Harkess (Eds.), Women working (pp. 206-224). Mayfield.

Uttley, S. (1981). Why social work? A comparison of British and New Zealand studies. The British Journal of Social Work, 11(1), 329-340. https://doi.org/10.1093/oxfordjournals.bjsw.a054641

Wagnild, G. M. (2016). The resilience scale user's guide: For the US English version of the Resilience Scale and the 14-item Resilience Scale (RS-14). Resilience Center.

Wagnild, G. M., \& Young, H. (1993). Development and psychometric evaluation of the resilience scale. Journal of Nursing Measurement, 1(2), 165-178. PMID: 7850498.

Wilson, G., \& McCrystal, P. (2007). Motivations and career aspirations of MSW students in Northern Ireland. Social Work Education, 26(1), 35-52. https://doi.org/10.1080/ 02615470601036534

Zugazaga, C., Surette, R., Mendez, M., \& Otto, C. (2006). Social worker perceptions of the portrayal of the profession in the news and entertainment media: An exploratory study. Journal of Social Work Education, 42(3), 623-636. https://doi.org/10.5175/JSWE.2006.200500502 


\section{Appendix}

\begin{tabular}{|c|c|c|c|}
\hline University & Pathway & Entry requirements & Other \\
\hline NUI Galway & MSW & $\begin{array}{l}\text { A Level } 8 \text { primary undergraduate degree } \\
\text { (minimum 2:2) in one of the following: } \\
\text { Bachelor Degree with a major in Social } \\
\text { Work, Sociology, Psychology Social Policy, } \\
\text { Social Science, Social Studies, Social Care, } \\
\text { Public \& Social Policy, Youth \& Family } \\
\text { Studies, Childhood Education, Childhood } \\
\text { Studies, Health \& Social Care, Community } \\
\text { Development, or B Social Sciences or } \\
\text { other relevant equivalent qualifications. } \\
\text { Applicants must submit a } 300 \text { word } \\
\text { statement of interest in social work \& } \\
\text { provide } 2 \text { reference letters (one academic } \\
\text { \& one work-related) }\end{array}$ & $\begin{array}{l}\text { Prior work experience in a related setting is } \\
\text { compulsory ( } 6 \text { months/approx. } 960 \text { hours) } \\
\text { in order to be eligible to apply. Relevant } \\
\text { supervised placement learning will } \\
\text { normally count for up to a maximum of } \\
240 \text { hours ( } 6 \text { weeks). }\end{array}$ \\
\hline QUB & UGR & $\begin{array}{l}\text { A Level grades } A B B \text {, Access course with an } \\
\text { average of } 70 \% \text { or equivalent }+ \text { GCSE } \\
\text { Maths }\end{array}$ & $\begin{array}{l}\text { Department of Health Incentive Scheme } \\
\text { offer a bursary of } £ 4000 \text { per annum }+ \\
£ 500 \text { contribution towards travel costs }\end{array}$ \\
\hline QUB & RGR & $\begin{array}{l}\text { Relevant Honours degree (minimum } \\
\text { standard 2:2) where at least one third of } \\
\text { the course comprises one or more of the } \\
\text { following: Sociology, Psychology, } \\
\text { Criminology, Social Policy/Social } \\
\text { Administration, or a degree in Law, } \\
\text { Teaching, Nursing, Community Work, } \\
\text { Youth Work, Early Childhood Studies, } \\
\text { Human Communication/Counselling, } \\
\text { Social Anthropology, Housing Studies, } \\
\text { Health and Social Care, Occupational } \\
\text { Therapy or other cognate subject. } \\
\text { Graduates in any other subjects (minimum } \\
\text { standard 2:2) who have successfully } \\
\text { completed a Postgraduate Certificate in } \\
\text { Education (PGCE).+ GCSE Mathematics or } \\
\text { equivalent }\end{array}$ & $\begin{array}{l}\text { Department of Health Incentive Scheme } \\
\text { offer a bursary of } £ 4000 \text { per annum }+ \\
£ 500 \text { contribution towards travel costs }\end{array}$ \\
\hline TCD & UGR & $\begin{array}{l}\text { School leavers with required } \mathrm{CAO}^{1} \text { points or } \\
\text { equivalent. } \\
\text { Mature students with relevant practice } \\
\text { experience will be selected by interview. }\end{array}$ & $\begin{array}{l}\text { Annual quota of } 45 \text { places includes both } \\
\text { school leavers \& mature students with } \\
\text { relevant practise experience }\end{array}$ \\
\hline TCD & MSW & $\begin{array}{l}\text { Level } 8 \text { Social Sciences degree (minimum } \\
\text { 2:1). Candidates with a primary degree } \\
\text { outside the social sciences must hold } \\
\text { a postgraduate award in social science } \\
\text { (min. } 2: 1 \text { ). }\end{array}$ & $\begin{array}{l}\text { Candidates will also be required to } \\
\text { demonstrate a minimum of } 850 \text { hours } \\
\text { practice experience (paid or voluntary) }\end{array}$ \\
\hline UCC & BSW & $\begin{array}{l}\text { MSAP }{ }^{2} \text { results, statement of interest form, CV } \\
\text { \& evidence \&/or knowledge in social } \\
\text { issues \& social work. The selection process } \\
\text { for shortlisted candidates includes group } \\
\text { \& individual interviews. There are no } \\
\text { official qualifications required to gain } \\
\text { entry but candidates will be judged on } \\
\text { relevant work \& life experience, potential } \\
\text { to complete a demanding undergraduate } \\
\text { programme of study \& commitment to } \\
\text { this field of activity. }\end{array}$ & $\begin{array}{l}\text { This is a mature students pathway only \& } \\
\text { students must be aged } 23 \text { or over by } 1^{\text {st }} \\
\text { January of first year of study. }\end{array}$ \\
\hline
\end{tabular}




\begin{tabular}{|c|c|c|c|}
\hline University & Pathway & Entry requirements & Other \\
\hline UCC & MSW & $\begin{array}{l}\text { Minimum 2:2 Bachelor of Social Science } \\
\text { degree or equivalent or degree with } \\
\text { minimum } 20 \text { credits in Social Policy \& } \\
\text { preferred modules of study including at } \\
\text { least one of Psychology, Sociology, } \\
\text { Economics or Social Work. }\end{array}$ & \\
\hline UCD & MSW & Minimum 2:2 & 420 hours relevant work experience \\
\hline UU & UGR & A Level grades BBB + GCSE Maths \& English & $\begin{array}{l}\text { Department of Health Incentive Scheme } \\
\text { offer a bursary of } £ 4000 \text { per annum }+ \\
£ 500 \text { contribution towards travel costs }\end{array}$ \\
\hline UU & RGR & Cognate Degree + GCSE Maths \& English & $\begin{array}{l}\text { Department of Health Incentive Scheme } \\
\text { offer a bursary of } £ 4000 \text { per annum }+ \\
£ 500 \text { contribution towards travel costs }\end{array}$ \\
\hline
\end{tabular}

